\title{
Is Co-Administration Curcumin and Piperine a Benefit in Preventing Metabolic Syndrome?
}

\author{
Carmine Finelli ${ }^{1,2 *}$ \\ ${ }^{1}$ Department of Internal Medicine, Ospedale Cav. R. Apicella - ASL Napoli 3 Sud, Via di Massa, 1, 80040 Pollena (Napoli), Italy. \\ ${ }^{2}$ Covid Hospital Boscotrecase - ASL Napoli 3 Sud, Via Lenza, 3, 80042 Boscotrecase (Napoli), Italy. \\ *Corresponding Author: Carmine Finelli, Department of Internal Medicine, Ospedale Cav. R. Apicella - ASL Napoli 3 Sud, Via di Massa, 1, \\ 80040 Pollena (Napoli), Italy.
}

Received date: December 14, 2021; Accepted date: December 30, 2021; Published date: January 05, 2022

Citation: Carmine Finelli (2022). Is Co-Administration Curcumin and Piperine a Benefit in Preventing Metabolic Syndrome?. J. Archives of Medical Case Reports and Case Study, 5(1); DOI:10.31579/2692-9392/099

Copyright: (C) 2022 Carmine Finelli, This is an open access article distributed under the Creative Commons Attribution License, which permits unrestricted use, distribution, and reproduction in any medium, provided the original work is properly cited.

\section{Abstract}

The metabolic syndrome, which includes obesity, insulin resistance, dyslipidemia, and hypertension, has gained importance due to its link to the development of cardiovascular disease and type 2 diabetes.

Key words: dyslipidemia; and hypertension; cardiovascular disease

\section{INTRODUCTION}

The metabolic syndrome, which includes obesity, insulin resistance, dyslipidemia, and hypertension, has gained importance due to its link to the development of cardiovascular disease and type 2 diabetes [1]. Metabolic problems are becoming a big problem in both developed and developing countries in today's world. Metabolic syndrome is becoming more prevalent over the world, posing a serious danger to global health because it accounts for 6-7 percent of all deaths. People with metabolic syndrome are five times more likely than those without it to develop type 2 diabetes and are twice as likely to die from a heart attack or stroke $[2,3]$. It is one of the world's most important public health crises, affecting more than one-third of the world's population, and it is spreading at an alarming rate. Despite considerable advancements in medical and pharmaceutical medication research, food, exercise, and nutritional supplementation play an important role in maintaining a healthy lifestyle and overall well-being, especially in the case of cardiovascular diseases. As a result, in the current circumstances, there is a pressing need to examine and focus our research on nutraceuticals and their role in metabolic syndrome.

Curcumin is a nontoxic, very promising natural chemical with antiinflammatory [4], hepato- and nephroprotective [5, 6], antioxidant, antibacterial, anticarcinogenic [7], and thrombosis-suppressing activities [8]. Curcumin comes from the root of the Curcuma longa Linn plant (family Zingiberaceae). Curcumin's therapeutic activities are limited by its water solubility and alkaline $\mathrm{pH}$ degradation, which reduces its bioavailability. Despite the fact that Curcuma longa has been examined for its medicinal benefits, more research into its anti-diabetic, antioxidant, and lipid peroxidation levels in diabetic rats is required. As a result of the aforementioned, curcumin, piperine, and quercetin in combination are in great demand.

Piperine is an alkaloid present in plants such as Piper nigrum L, or black pepper, that has been demonstrated to help in drug absorption. It increases the bioavailability (serum concentration) of oral curcumin by inhibiting glucuronidation metabolism [9]. Because it aids in the prevention of curcumin metabolic conversion, a second bioavailability booster, such as quercetin, can boost absorption even more.

Pepper's principal pungent component, piperine, is an alkaloid with a variety of therapeutic benefits. It's also been shown to improve the bioavailability of nutritional and botanical compounds. Despite its exceptional therapeutic capabilities, piperine's pharmacological activities have been limited due to its low water solubility. The bio-active molecule's low solubility in aquatic environments underscores the need for new approaches that can help with long-term natural product extraction while also being environmentally friendly and energy-efficient. Among the advanced techniques used for piperine extraction are supercritical $\mathrm{CO} 2$ extraction, ultrasound and microwave-assisted extractions, as well as IL and enzyme-assisted extractions, all of which have some strengths and advantages over traditional methods. However, each method has its own set of flaws and limitations. Although some research has been done on extracting piperine from pepper and purifying it for biomedical uses, nothing has been done on using the derived piperine directly for medicinal purposes. Piperine's low water solubility is a major stumbling barrier in its development as a drug in the lab. Despite recent efforts to increase piperine bioavailability using nanoformulations and lipid body encapsulation, there is still a long way to go before it can be utilized as a pharmaceutical. The earliest results for medicinal usage of nanoformulated piperine are promising, and a bright 
future for piperine therapeutic exploitation can be predicted thanks to recent breakthroughs in biotechnology.

Therefore, the co-administration of curcumin and piperine seems to be a feasible strategy to increase the bioavailability of curcumin and to potentiate their effect on the blood lipids reduction at the same time. Although proposed mechanisms of action were previously reported [10-12], preclinical and clinical trials describing the effect of curcumin and piperine co-administration on serum lipids and cardiovascular events are restricted [13 - 15]. In animal and human clinical investigations, the combination of curcumin and piperine had a favorable effect on lipid profile by lowering total cholesterol, triglycerides, and LP(a) while boosting HDLC. Despite the fact that no long-term clinical trial evaluating the effect of curcumin and piperine co-administration on cardiovascular events has been conducted, secondary serum markers such as glucose, AST, and ALP, as well as an increase in CAT and SOD, have been identified as ways to reduce cardiovascular risk. A meta-analysis or a more standardized long-term clinical trial should be conducted as a result.

In conclusion, research suggests that co-administration of curcumin and piperine at different doses can help decrease serum lipids. There is insufficient direct evidence of the benefit of decreasing cardiovascular risk in preventing cardiovascular events and metabolic syndrome. The issue of safety and toxicology is still up in the air.

Disclosure statement: The author declare that there are no conflicts of interest.

\section{References}

1. Finelli C, Sommella L, Gioia S, La Sala N, Tarantino G. Should visceral fat be reduced to increase longevity?. Ageing Res Rev. 2013;12(4):996-1004. doi:10.1016/j.arr.2013.05.007.

2. Wilson PW, D'Agostino RB, Parise H, Sullivan L, Meigs JB. Metabolic syndrome as a precursor of cardiovascular disease and type 2 diabetes mellitus. Circulation. 2005;112(20):30663072. doi:10.1161/CIRCULATIONAHA.105.539528.

3. Barrett-Connor E, Wingard D, Wong N, Goldberg R. Chapter 18: Heart disease and diabetes. In: Cowie CC, Casagrande SS, Menke A, et al, eds. Diabetes in America, 3rd ed. NIH Pub No. 17-1468. National Institutes of Health; 2018:18.1-18.30.

4. Pepe G, Calce E, Verdoliva V, et al. Curcumin-Loaded Nanoparticles Based on Amphiphilic Hyaluronan-Conjugate Explored as Targeting Delivery System for Neurodegenerative Disorders. Int J Mol Sci. 2020; 21 (22): 8846. Published 2020 Nov 23. doi:10.3390/ijms21228846.

5. Sanjeev S, Bidanchi RM, Murthy MK, Gurusubramanian G, Roy VK. Influence of ferulic acid consumption in ameliorating the cadmium-induced liver and renal oxidative damage in rats. Environ Sci Pollut Res Int. 2019; 26 (20): 20631-20653. doi:10.1007/s11356-019-05420-7.

6. Pivari F, Mingione A, Brasacchio C, Soldati L. Curcumin and Type 2 Diabetes Mellitus: Prevention and Treatment. Nutrients. 2019; 11 (8): 1837. Published 2019 Aug 8. doi:10.3390/nu11081837.

7. Alizadeh N, Malakzadeh S. Antioxidant, antibacterial and anti-cancer activities of $\beta$-and $\gamma$-CDs/curcumin loaded in chitosan nanoparticles. Int J Biol Macromol. 2020; 147: 778791. doi:10.1016/j.ijbiomac.2020.01.206.

8. Chung TW, Tyan YC, Lin SW, Yang MH, Liu YH, Wang RP. Developing photothermal-responsive and anti-oxidative silk/dopamine nanoparticles decorated with drugs which were incorporated into silk films as a depot-based drug delivery. Int J Biol Macromol. 2021; 185: 122-133. doi:10.1016/j.ijbiomac.2021.06.084.

9. Wang R, Han J, Jiang A, et al. Involvement of metabolismpermeability in enhancing the oral bioavailability of curcumin in excipient-free solid dispersions co-formed with piperine. Int J Pharm. 2019; 561: 9-18. doi:10.1016/j.ijpharm.2019.02.027.

10. Carrizzo A, Izzo C, Forte M, et al. A Novel Promising Frontier for Human Health: The Beneficial Effects of Nutraceuticals in Cardiovascular Diseases. Int J Mol Sci. 2020; 21 (22): 8706. Published 2020 Nov 18. doi:10.3390/ijms21228706.

11. Duc HN, Oh H, Kim MS. Effects of Antioxidant Vitamins, Curry Consumption, and Heavy Metal Levels on Metabolic Syndrome with Comorbidities: A Korean Community-Based Cross-Sectional Study. Antioxidants (Basel). 2021; 10 (5): 808. Published 2021 May 19. doi:10.3390/antiox10050808.

12. Pillai SC, Borah A, Le MNT, Kawano H, Hasegawa K, Kumar DS. Co-Delivery of Curcumin and Bioperine via PLGA Nanoparticles to Prevent Atherosclerotic Foam Cell Formation. Pharmaceutics. 2021; 13 (9): 1420. Published 2021 Sep 8. doi:10.3390/pharmaceutics 13091420

13. Gu Y, Xia H, Chen X, Li J. Curcumin Nanoparticles Attenuate Lipotoxic Injury in Cardiomyocytes Through Autophagy and Endoplasmic Reticulum Stress Signaling Pathways. Front Pharmacol. 2021;12:571482. Published 2021 Mar 11. doi:10.3389/fphar.2021.571482

14. Haq IU, Imran M, Nadeem M, Tufail T, Gondal TA, Mubarak MS. Piperine: A review of its biological effects. Phytother Res. 2021;35(2):680-700. doi:10.1002/ptr.6855.

15. Stasiłowicz A, Tykarska E, Lewandowska $\mathrm{K}$, et al. Hydroxypropyl- $\beta$-cyclodextrin as an effective carrier of curcumin - piperine nutraceutical system with improved enzyme inhibition properties. J Enzyme Inhib Med Chem. 2020;35(1):1811-1821.

doi:10.1080/14756366.2020.1801670. 
(C) (†) This work is licensed under Creative Commons Attribution 4.0 License

To Submit Your Article Click Here: Submit Manuscript

DOI:10.31579/2692-9392/099
Ready to submit your research? Choose Auctores and benefit from:

* fast, convenient online submission

* rigorous peer review by experienced research in your field

* rapid publication on acceptance

* authors retain copyrights

* unique DOI for all articles

* immediate, unrestricted online access

At Auctores, research is always in progress.

Learn more www.auctoresonline.org/journals/archives-of-medical-casereports-and-case-study 